\title{
Biomorphological Alterations Induced by an Anti-juvenile Hormonal Compound, 2-(2-EthoxyEthoxy)Ethyl Furfuryl Ether, on Three Species of Triatominae Larvae (Hemiptera, Reduviidae)
}

\author{
José Jurberg, Cleber Galvão/ ${ }^{+}$, William S Bowers*, Eloi S Garcia**, \\ Patricia Azambuja**
}

\begin{abstract}
Laboratório Nacional e Internacional de Referência em Taxonomia de Triatomíneos, Departamento de Entomologia **Departamento de Bioquímica e Biologia Molecular, Instituto Oswaldo Cruz, Av. Brasil 4365, 21045-900 Rio de Janeiro, RJ, Brasil *Laboratory of Chemical Ecology, Department of Entomology,

The University of Arizona, Tucson, AZ 85721, USA
\end{abstract}

\begin{abstract}
Applied topically to larvae of Rhodnius prolixus Stal, Triatoma infestans (Klug) and Panstrongylus herreri Wygodzinsky, vectors of Trypanosoma cruzi, the causative agent of Chagas'disease, a synthetic, furan-containing anti-juvenile hormonal compound, 2-(2-ethoxyethoxy)ethyl furfuryl ether induced a variety of biomorphological alterations, including precocious metamorphosis into small adultoids with adult abdominal cuticle, ocelli, as well as rudimentary adultoid wings. Some adultoids died during ecdysis and were confined within the old cuticle. The extension of these biomorphological responses is discussed in terms of the complexity of the action of anti-juvenile hormonal compounds during the development of triatomines.
\end{abstract}

Key words: Rhodnius prolixus - Triatoma infestans - Panstrongylus herreri - adultoid - anti-juveline hormone

From the beginning of the studies of the action of precocenes in insects (Bowers 1976, 1977, Bowers et al. 1976), the compounds with anti-juvenile hormonal (AJH) activity are considered important new approaches to insect control. These compounds cause the developing of premature stages, i.e., they induced diminutive and sterile adults named adultoids (Bowers 1976, 1977, 1982, Azambuja et al. 1981). Phytochemicals with AJH activities in insects have been discovered in several plants (Bowers et al.1976, Garcia et al. 1984, Bowers \& Areguilin 1987, Garcia \& Azambuja 1987). Several AJHs have been obtained by synthetic chemical routes (Quistad et al. 1981, Kuwano

This work was supported by Conselho Nacional de Desenvolvimento Científico e Tecnológico (CNPq) to ESG, PA and JJ, Programa de Apoio à Pesquisa Estratégica em Saúde (PAPES, FIOCRUZ) to PA, BIRD/ FNS/FIOCRUZ contract number 027/93 and European Union (STD-TS3-CT-920092) to JJ and CG.

Part of this paper was presented in the XXI Annual Meeting on Basic Research in Chagas'Disease, Caxambu, MG, Brasil, 1994.

${ }^{+}$Corresponding author. Fax: +55-21-290.9339. e-mail: galvao@dcc001.cict.fiocruz.br

Received 31 October 1996

Accepted 19 December 1996 et al. 1983, Staal 1986, Brooks et al. 1988). The effects of precocenes were investigated in different triatomine species. For example, Azambuja et al. (1981), Garcia et al. (1984, 1988) and Jurberg et al. $(1982,1984,1986)$ described the actions of precocene in Rhodnius prolixus, Panstrongylus megistus and Triatoma infestans.

Recently, it has been demonstraded that novel furanyl ethers have potent AJH activity in Oncopeltus fasciatus Dallas (Bowers et al. 1995) and in triatomines (Azambuja et al. 1996) inducing precocious metamorphosis and other modifications in these insects. In this investigation we examine the biomorphological effects of 2-(2ethoxyethoxy)ethyl furfuryl ether (EEFE), one of the most active of the furanyl ether AJHs, on the hematophagous bugs, $R$. prolixus, $T$. infestans and Panstrongylus herreri, three vectors of Trypanosoma cruzi, a protozoan that causes Chagas'disease in Latin-America.

\section{MATERIALS AND METHODS}

Insects and feeding - Carefully staged third-instar larvae of $R$. prolixus Stal, 1859, T. infestans (Klug, 1834) and P. herreri Wygodzinsky, 1948, reared and maintained in the Department of Entomology, FIOCRUZ, were used throughout this investigation. Weights just before feeding ranged from $4.5 \mathrm{mg}$ for Rhodnius to $7.6 \mathrm{mg}$ for 
Pastrongylus. Following ecdysis, the insects were starved for 30-35 days and then fed on mouse. Only fully engorged insects were used in all treatment. The insects were maintained at $28^{\circ} \mathrm{C}$ during the whole experiment as described previously (Garcia et al. 1988).

Topical treatment - Topical treatments were performed on groups of 20-30 third-instar larvae of these triatominae species. EEFE at a concentration of $60 \mu \mathrm{g}$ in $0.5 \mu \mathrm{l}$ of acetone was applied to the ventral surface of the abdomen on the fourth day before feeding. The biomorphological alterations induced by EEFE were determined by the external inspection of the adultoids produced, in particular, on the external genitalia of males of these three species of triatomines. Controls received solvent treatment only.

Genitalia procedures - Genitalia was taken up from insects with morphological alterations, heated in $10 \% \mathrm{KOH}$, and manipulated in phenol up to the mounting in Canada balsam as previously described by Jurberg et al. (1984). The figures were drawn using stereoscopic microscope connected to a camara lucida.

\section{RESULTS}

General external morphology - Visual inspection of the adultoids demonstrated that topical application with EEFE produced many $R$. prolixus adultoids with fully adult abdominal cuticle, ocelli, tibial adhesive organs, absence of the setiferous tubercle, pronotum within collar. Antero-lateral angles and anterior and posterior lobes were abnormal, and the rudimentary adultoid wings never attained the first abdominal segment but possessed full articulation with the thorax. General biomorphological alterations in the other two species of triatomines were similar to these described above for Rhodnius.

We also observed that adultoids induced by topical application with EEFE had further morphological responses: (i) sometimes died during ecdysis and were confined within the old cuticle and, normally, the head was recurved to the ventral surface of the abdomen in all species tested (Fig.1); these morphological alterations had different intensity varying with the period of moulting and the species of triatomines (Figs 2a,b,c and 3 ); (ii) in the adultoid of $P$. herreri the filiform antennae did insert far from the anterior to the eyes and (iii) $R$. prolixus presented pronotum and mesonotum separated, metanotum with the posterior border visible and rudimentary scutellum between the bases of the forewings; sometimes the scutellum was absent.

Male external genitalia - The main alterations

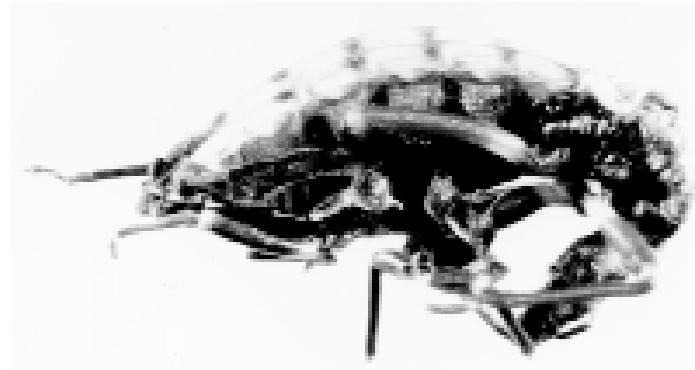

Fig.1: induction of adultoids in third-instar larvae of Panstrongylus herreri by the treatment of EEFE at a concentration of $60 \mu \mathrm{g}$ on the fourth day before feeding.

of the external genitalia of males in adultoids of the three species of triatomines experienced are: (i) T. infestans presented abnormal phallus formed by a hard chitinized plate with any morphological characteristics related to normal structures including the absence of articulation that facilitates the phallus gets out of the pygophore (Fig. 4a,b); (ii) $P$. herreri had neither the male external genitalia nor the formation of globulous pygophore (Fig. 5); and (iii) $R$. prolixus adultoids had pygophore linked to the 10th abdominal segment. In addition, we observed both no genital structures inside the pygophore and an abnormal rectangular plaque with slightly curvature showing the base of the pygophore (Fig. 6 a,b). The normal aspect of these structures is highly complex and therefore we prefer to refer to the figures already shown by Lent and Jurberg $(1969,1975,1978)$. Finally, Table demonstrated by comparison that the morphological alterations induced by EEFE are similar to those induced by the classical AJH compound.

\section{DISCUSSION}

In the present paper, we investigated the biomorphological responses on larvae of three species of triatomines induced by the most active furanyl derivatives, EEFE. In fact, we already studied the effect of EEFE on several species of triatomines giving the paucity of information on the ecdysial stasis, delay of moulting, lethality, production of precocious adultoids under different modes of treatments, and comparison of this compound with precocene II (Azambuja et al. 1996). Now, we extend these findings and describe with more details the biomorphological alterations caused by the topical treatment of 3rd instar-larvae of $R$. prolixus, $T$. infestans and $P$. herreri. Our present results, considering in particular the male external genitalia, demonstrate considerable varia- 

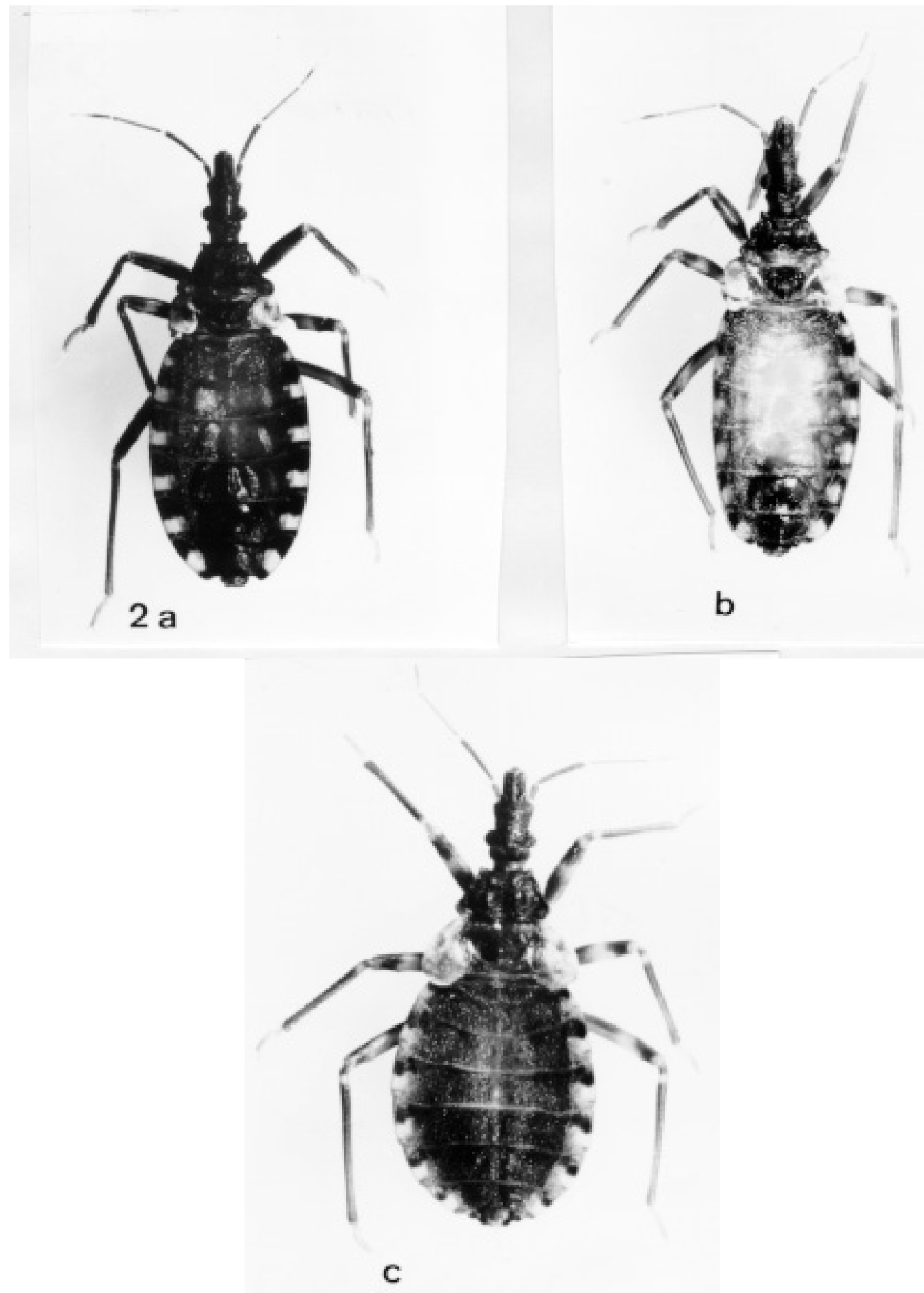

Fig. 2a,b,c: induction of adultoids in the third-instar larvae of Triatoma infestans by the treatment of EEFE at a concentration of $60 \mu \mathrm{g}$ on the fourth day before feeding. 


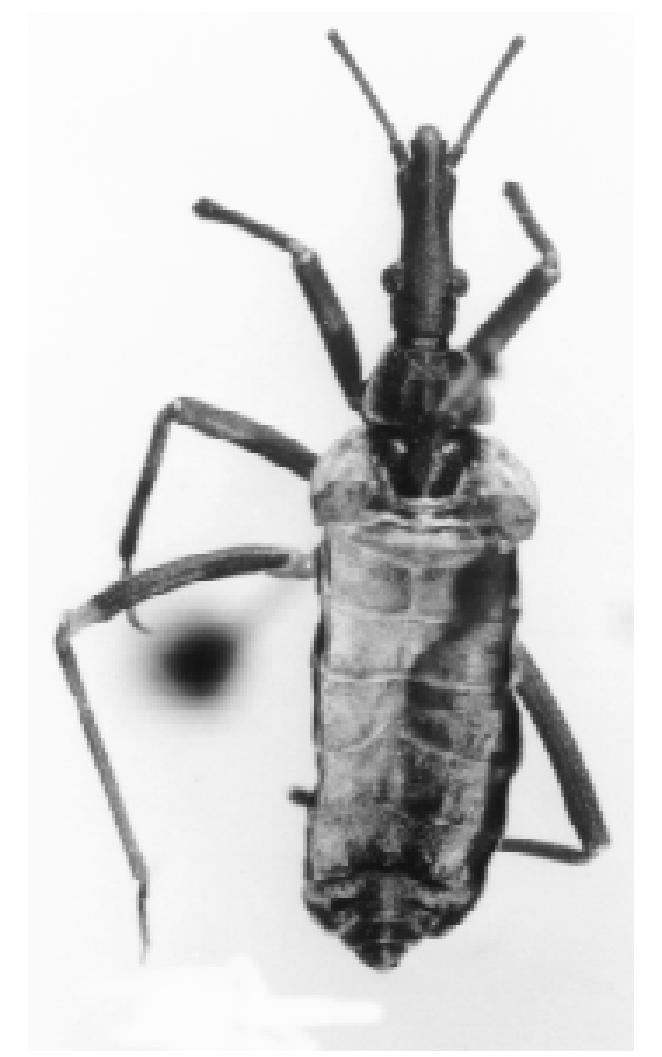

Fig. 3: induction of adultoids in the third-instar larvae of Rhodnius prolixus by the treatment of EEFE at a concentration of $60 \mu \mathrm{g}$ on the fourth day before feeding. tion in sensitivity amongst species. For example, $P$. herreri was more sensitive to EEFE than $R$. prolixus and T. infestans if we observe the alterations induced in the male external genitalia. In the former species it was not found genitalia and formation of the characteristic pygophore, while the latter species demonstrated abnormal phallus (T. infestans) and pygophore ( $R$. prolixus). However, these three species demonstrated about equivalent sensitivity when we consider the general external morphology. It is interesting to point out that the induction of precocious metamorphosis was greater in $T$. infestans than in $R$. prolixus and $P$. herreri (Azambuja et al. 1996).

Since the mode of action, species specificity and spectrum of activity of the EEFE is presently unknow (Bowers et al. 1995, Azambuja et al. 1996) it seems valuable to speculate that (i) it is possible that the difference of sensitivity between the triatomine species studies was due to the dynamics of cuticular penetration, pharmacokinetics and metabolisms of the compound and (ii) EEFE may not affect the corpus allatum but terminate juvenile hormone $(\mathrm{JH})$ production/release rather than alter or compete with JH cellular receptor, since precocious metamorphosis was inhibited by therapy with JHA (Bowers et al. 1995, Azambuja \& Garcia unpublished data). Notwithstanding these speculations, our studies suggest that the furanylderivatives should be studied in other species of triatomines.

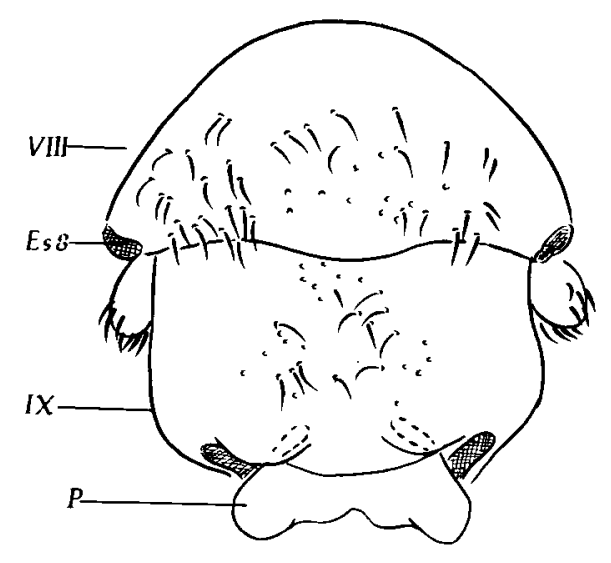

a

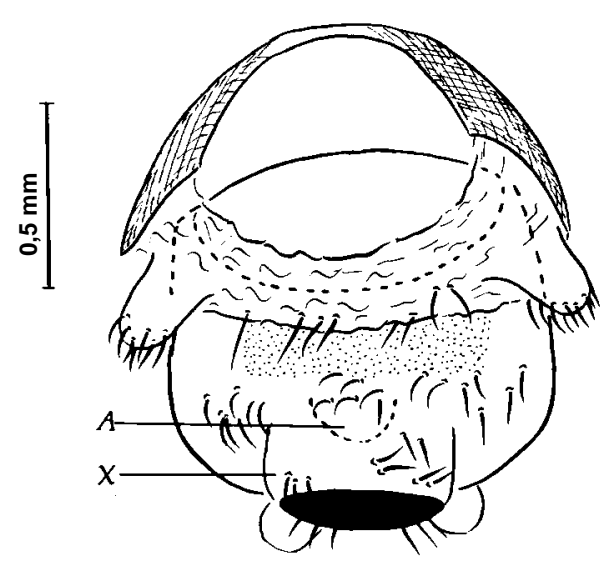

b

Fig. 4: pygophore or 9th abdominal segment of an adultoid of Triatoma infestans obtained by the treatment of EEFE at a concentration of $60 \mu \mathrm{g}$ on the fourth day before feeding. a-ventral and b-dorsal views. VIII=8th segment; Es8=stigma of the 8th segment; IX=pygophore or 9th segment; $\mathrm{P}=$ phallus; $\mathrm{A}=$ anus; $\mathrm{X}=10$ th segment. 


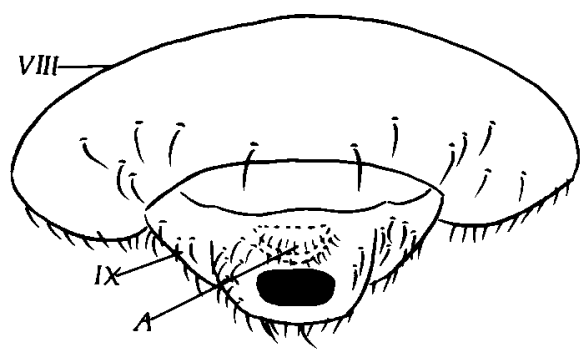

a

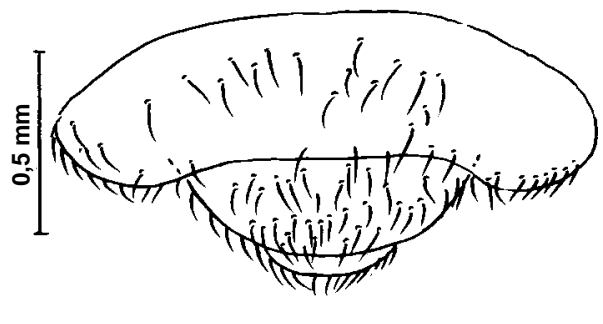

b

Fig. 5: last abdominal segments of an adultoid of Panstrongylus herreri obtained by the treatment of EEFE at a concentration of $60 \mu \mathrm{g}$ on the fourth day before feeding. a-dorsal and b-ventral views. VIII=8th segment; IX=pygophore or 9th segment; $A=a n u s$.

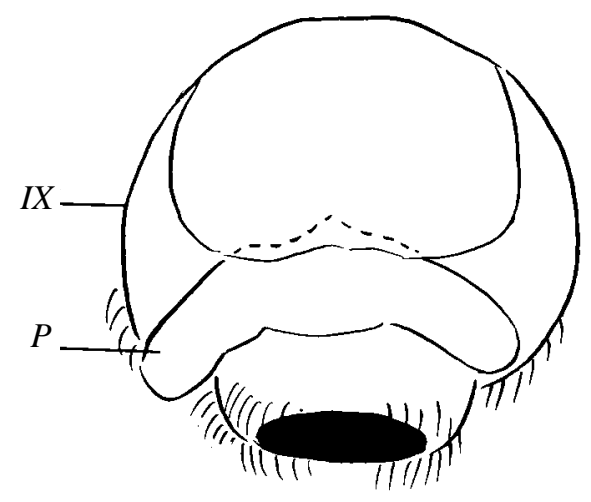

a

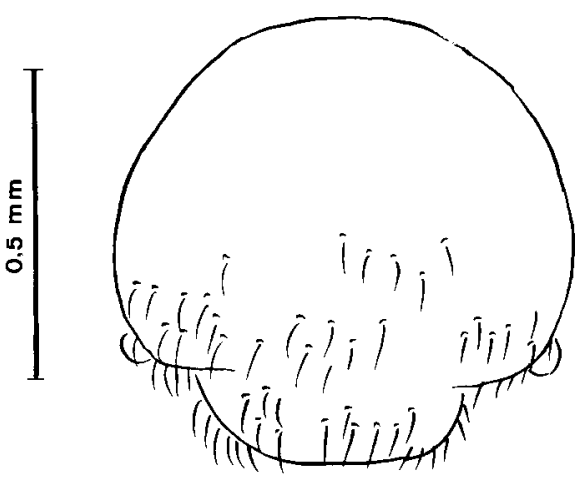

b

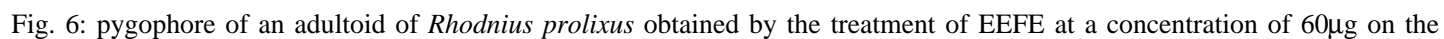
fourth day before feeding. a-dorsal and $b$-ventral views. IX=pygophore or 9 th segment; $P=$ phallus.

\section{TABLE}

Morphological alterations induced by precocene II and EEFE [2-(2-ethoxyethoxy) ethyl furfuryl ether] on triatominae larvae

\begin{tabular}{|c|c|c|c|c|}
\hline Species & Compounds & Instar larvae & $\begin{array}{l}\text { Topical treatment } \\
(\mu \mathrm{g} / \text { larva })\end{array}$ & $\begin{array}{l}\text { Morphological } \\
\text { alterations }\end{array}$ \\
\hline Triatoma infestans & precocene & fourth & $200-400$ & $\begin{array}{l}\text { Ecdysis to adultoids } \\
\text { (Jurberg et al. 1986) }\end{array}$ \\
\hline Rhodnius prolixus & precocene & third /fourth & $10-30$ & $\begin{array}{l}\text { Adultoids with } \\
\text { abnormal genitalia } \\
\text { (Jurberg et al. 1984) }\end{array}$ \\
\hline Panstrongylus megistus & precocene & third fourth & $10-80$ & $\begin{array}{l}\text { Adultoids. Genitalia } \\
\text { with internal and } \\
\text { external atrophies } \\
\text { (Jurberg et al. 1982) }\end{array}$ \\
\hline R. prolixus & EEFE & third & 60 & $\begin{array}{l}\text { Adultoids. Abnormal } \\
\text { pygophore (present paper) }\end{array}$ \\
\hline T. infestans & EEFE & third & 60 & $\begin{array}{l}\text { Adultoids. Abnormal } \\
\text { phallus (present paper) }\end{array}$ \\
\hline P. herreri & EEFE & third & 60 & $\begin{array}{c}\text { No male external } \\
\text { genitalia (present paper) }\end{array}$ \\
\hline
\end{tabular}




\section{REFERENCES}

Azambuja P, Garcia ES, Bowers WS 1996. Biological activity of a furanyl anti-juvenile hormonal compound on triatominae larvae. Pestic Sci 47: 159-164.

Azambuja P, Garcia ES, Ribeiro JMC 1981. Effects of ecdysone on the metamorphosis and ecdysis prevention induced by precocene II in Rhodnius prolixus. Gen Comp Endocrinol 45: 100-104.

Bowers WS 1976. Discovery of insects antiallatotropins, p. 394-408. In LI Gilbert, The Juvenile Hormone, Plenun, New York.

Bowers WS 1977. Anti-juvenile hormone from plants: Chemistry and biological activity, p. 129-142. In GB Marini-Bettolo, Natural Products and the Protection of Plants, Proceedings of the Pontifical Academy of Science, Vatican City.

Bowers WS 1982. The precocenes, p. 517-523. In GH Downer, H Laufer (eds), Invertebrate Endocrinology, Alan R Liss, New York.

Bowers WS, Areguillin M 1987. Discovery and identification of an antijuvenile hormone from Chrysanthemum cornarium. Mem Inst Oswaldo Cruz 82: 5154.

Bowers WS, Ohta T, Cleere JF, Marsella PA 1976. Discovery of antijuvenile hormones in plants. Science 193: 542-547.

Bowers WS, Unnithan GC, Fukushima J, Toda J, Sugiyama T 1995. Synthesis and biological activity of furanyl anti-juvenile hormonal compounds. Pestic Sci 43: 1-11.

Brooks G, Ottridge AP, Mace DW 1988. The effect of some furochromene and benzochromene analogues of 2,2-dimethyl-7-methoxychromene (Precocene I) and benzofuran precursors on Oncopeltus fasciatus (Dallas) and Locusta migratoria migratorioides (R\&F). Pestic Sci 22: 41-50.

Garcia ES, Azambuja P 1987. Induction of ecdysial stasis with structurally analogous proallatotoxins, $\mathrm{p}$. 109-112. In R Grenhald, TR Roberts (eds), Pesticide Science and Biotechnology, Blackwell Sci Publications.

Garcia ES, Azambuja P, Bowers WS 1984. Comparison of structurally analogous allatotoxins on the molting and morphogenesis of Rhodnius prolixus, and the reversal of ecdysial stasis by ecdysone. Arch Insect Biochem Physiol 1: 367-373.

Garcia ES, Azambuja P, Feder D, Bowers WS 1988. Inhibition of ecdysteroid production in nymphs of Rhodnius prolixus treated with ethoxyprecocene II. Arch Insect Biochem Physiol 8: 127-134.

Jurberg J, Costa JM, Gonçalves TCM, Garcia ES, Azambuja P 1984. Efeitos morfogênicos de precoceno II em ninfas de Rhodnius prolixus (Stal, 1859) (Hemiptera-Triatominae). Mem Inst Oswaldo Cruz 79: 397-407.

Jurberg J, Costa JM, Gonçalves TCM, Garcia ES, Azambuja P 1986. Alterações biomorfogênicas causadas pela aplicação de precoceno II em ninfas de Triatoma infestans (Klug, 1834) (Hemiptera, Reduviidae, Triatominae). Mem Inst Oswaldo Cruz 81: 171-184.

Jurberg J, Gonçalves TCM, Oliveira-Filho 1982. Alterações morfológicas provocadas pela aplicação de precoceno II em Panstrongylus megistus (Burmeister, 1835) (Hemiptera, Reduviidae, Triatominae). Rev brasil Biol 42: 527-538.

Kuwano E, Takeya R, Eto M 1983. Terpenoid imidazole: New anti-juvenile hormone. Agric Biol Chem 47: 921-923.

Lent H, Jurberg J 1969. O Gênero Rhodnius Stal, 1859, com um estudo sôbre a genitália das espécies (Hemiptera, Reduviidae, Triatominae). Rev brasil Biol 29: 487-560.

Lent H, Jurberg J 1975. O Gênero Panstrongylus Berg, 1879, com um estudo sobre a genitália externa das espécies (Hemiptera, Reduviidae, Triatominae). Rev brasil Biol 35: 379-438.

Lent H, Jurberg J 1978. Estudo comparativo da genitália externa masculina de seis espécies de Triatoma Laporte, 1832 que mais freqüentemente habitam o domicílio humano no Brasil (Hemiptera, Reduviidae). Rev brasil Biol 38: 931-944.

Quistad GB, Cerf DC, Schooley DA, Staal GB 1981. Fluoromevalonate acts as an inhibitor of insect juvenile hormone biosynthesis. Nature (Lond) 289: 176-177.

Staal GB 1986. Anti-juvenile hormone agents. Ann Rev Entomol 31: 391-429. 